\title{
Financeirização e a produção do espaço urbano no Brasil: uma contribuição ao debate
}

Daniel Sanfelici. Universidade de São Paulo, São Paulo, Brasil.

RESUMo | Nos últimos dez anos no Brasil, o volume de contratações de financiamento habitacional cresceu rapidamente. Paralelamente a esse crescimento nas contratações, há uma clara tendência ao crescimento na emissão de papéis financeiros com lastro na atividade imobiliária, como Certificados de Recebíveis Imobiliários (CRIs) e cotas de fundos de investimento imobiliário. Tendo em vista esse contexto, em que canais financeirizados de investimento imobiliário ganham maior centralidade e após uma breve revisão bibliográfica, o artigo pretende olhar para esse processo colocando em destaque como a relação entre as grandes incorporadoras e o mercado de capitais transformou os negócios imobiliários no Brasil. Particularmente, atenta-se para o fato de que a articulação com as finanças induziu a um processo de dispersão territorial e de ampliação da escala do investimento. $\mathrm{O}$ artigo conclui sugerindo que a financeirização representa um reordenamento escalar do processo de urbanização.

PALAVRAS CHAVE | reestruturação econômica, mercado imobiliário, reescalamento.

ABSTRACT | Over the past ten years, the number of mortgage loan originations has grown rapidly in Brazil. At the same time, there is a clear trend toward the issuing of financial instruments backed by property revenues, such as the Certificados de Recebiveis Imobiliarios (CRIs) and shares in real estate investment trusts. Against the backdrop of this growing centrality of financialized channels for property investment, after a brief theoretical discussion, we have looked at this trend by focusing on how the relationship between large developers and capital markets has transformed the property sector in Brazil. We have noted, particularly, that the connection with financial markets has encouraged strategies of territorial expansion and growing scale of investment among large developers. The paper concludes by suggesting that financialization in property markets amounts to a rescaling of the urban process.

KEY WORDS | economic restructuring, real estate market, rescaling.

Recibido el 27 de marzo de 2012, aprobado el 19 de noviembre de 2012

E-mail: danielsanfelici@gmail.com 


\section{Introdução}

A persistência de um quadro conjuntural de severa recessão nos países desenvolvidos, com possíveis desdobramentos globais, mesmo passados quatro anos do desencadeamento da crise subprime nos Estados Unidos, coloca à mostra a fragilidade de um crescimento econômico centrado na acumulação de capital na esfera financeira. Os níveis alarmantes de envididamento dos Estados e das famílias em inúmeros países - uma manifestação da hiperextensão do sistema de crédito em relação às possibilidades concretas de acumulação - poderiam sugerir a dissolução de uma configuração peculiar ao capitalismo dos últimos vinte a trinta anos. A esse fator, soma-se uma conscientização maior e em nível global - ilustrada, por exemplo, pelo movimento Occupy Wall Street, entre outros - a respeito das consequências nefastas da hipertrofia da esfera financeira sobre aspectos como a distribuição de renda e de riqueza e o acesso à moradia. No entanto, o que se assiste é a uma reiteração de medidas em vários países que, longe de frear o ímpeto expansivo das finanças, reforçam um padrão de acumulação cujo desdobramento inevitável haveria de ser a crise de 2008.

Nesse contexto, o interesse em desvendar as repercussões da financeirização sobre dimensões variadas da vida social vem crescendo consideravelmente nas ciências sociais. Há um reconhecimento, cada vez maior, de que os fenômenos atinentes às finanças não se limitariam às altas esferas de especulação internacional com moedas e papéis, possuindo também importantes ramificaçôes na prática cotidiana das sociedades. A investigação acerca dos elos entre financeirização e a produção do espaço urbano aparece, nessas circunstâncias, como um campo importante de pesquisa que vem se desenvolvendo mais fortemente nos últimos anos. Esse artigo pretende contribuir com pesquisas já existentes nesse campo, refletindo acerca da relação entre financeirização e a produção do espaço urbano no Brasil atual. A elaboração do artigo apóia-se, fundamentalmente, em uma pesquisa empírica ainda em curso, que focaliza a trajetória recente de um grupo de grandes incorporadoras/ construtoras brasileiras após a abertura de capital, com o propósito de avaliar suas implicações sobre o processo de urbanização no Brasil.

A primeira parte desse artigo dedica-se a uma breve discussão teórica acerca dos fundamentos sociais e econômicos da financeirização. Ressalta-se, aqui, que a financeirização não pode ser compreendida simplesmente como uma dominação do setor financeiro sobre o setor produtivo, sob o risco de simplificar um fenômeno que possui uma complexidade apreciável. Em vez de postular uma exterioridade entre o setor financeiro e o restante da economia, na qual o primeiro apareceria como a origem do fenômeno de financeirização, seria necessário, antes, reconhecer que um dos traços centrais da financeirização reside na crescente penetração de práticas financeirizadas por todas as relações econômicas e sociais relevantes do capitalismo atual. A urbanização pode, então, ser compreendida como um fenômeno que se encontra, crescentemente, sob a influência do capital portador de juros. 
$\mathrm{Na}$ segunda parte, coloca-se em destaque alguns dos desdobramentos do processo de financeirização para pensar as metrópoles brasileiras hoje. Embora se reconheça que se trata, ainda, de um fenômeno incipiente no Brasil, o trabalho procura examinar a presença de interesses financeiros na produção do espaço das metrópoles, enfocando as mudanças de estratégia das grandes incorporadoras/ construtoras após a abertura de capital em 2006/7, que permitiu a participação de grandes fundos de aplicação financeira na composição acionária dessas empresas. Segundo o argumento desenvolvido, não apenas a abertura de capital potencializou a extração de rendas urbanas nas maiores metrópoles do Brasil, como também produziu efeitos visíveis sobre a estruturação das cidades.

\section{As múltiplas dimensões da financeirização}

O sistema de crédito é uma peça-chave na arquitetura da acumulação capitalista. Ao adiantar recursos ociosos àqueles que não dispõem desses recursos em determinado ponto do tempo, o sistema de crédito permite uma compatibilização entre diferentes temporalidades do processo de acumulação e, de tal forma, contribui para acelerar o tempo de rotação dos capitais e diminui os custos relacionados com a circulação (Itoh \& Lapavitsas, 1999; Harvey, 1999). Sua presença é, ademais, indispensável em função de seu papel coordenador, ou seja, o sistema de crédito é capaz de coletar dinheiro ocioso de todos os poupadores da sociedade e alocar esse dinheiro para as atividades que apresentam maior potencial de produzir mais-valia, induzindo nesse movimento, uma equalização das taxas de lucro entre setores e regiões. Nesse sentido, é válido afirmar que o capitalismo não poderia existir sem um sistema de crédito cada vez mais sofisticado para atender suas necessidades de reprodução.

No entanto, quando se fala em financeirização não está se falando, exclusivamente, das instituições e agentes que compõem o núcleo do sistema de crédito (bancos, fundos de investimento, etc), em que pese o papel central desses agentes na formulação do conceito. A noção de financeirização, que ganhou maior atenção nas ciências sociais nos últimos anos, repousa sobre uma compreensão de que as finanças encontram-se cada vez mais associadas com uma vasta gama de atividades econômicas e sociais que ultrapassam a esfera financeira strictu sensu, e de que sua intrusão em todos os interstícios da sociedade reflete uma situação peculiar do capitalismo nos últimos vinte a trinta anos. Mais do que isso, a hiperextensão das finanças nos últimos anos teria suscitado o florescimento de uma lógica financeira geral, que agora permeia todas as atividades capitalistas e mesmo a reprodução da força de trabalho. Diferentes trabalhos, ao longo dos últimos anos, vêm tentando explorar e especificar os sentidos da financeirização para além de uma noção, presente em algumas correntes heterodoxas da economia, de uma dominação do setor financeiro ou dos bancos sobre a economia produtiva, ou de uma hegemonia de agentes financeiros sobre o capital industrial, perspectiva que tende, muitas vezes, a negligenciar a complexidade do fenômeno. 
José Carlos Braga foi talvez um dos primeiros a tratar o problema dessa forma mais abrangente. Em artigo escrito na década de 1990, o autor afirma que a financeirização representa um

padrão sistêmico porque (...) está constituída por componentes fundamentais da organização capitalista, entrelaçados de maneira a estabelecer uma dinâmica estrutural segundo princípios de uma lógica financeira geral. Neste sentido, ela não decorre apenas da práxis de segmentos ou setores - o capital bancário, os correntistas tradicionais - mas, ao contrário, tem marcado as estratégias de todos os agentes privados relevantes, condicionado a operação das finanças e dispêndios públicos, modificado a dinâmica macroeconômica. Enfim, tem sido intrínseca ao sistema tal como ele está atualmente configurado (Braga, 1997, p. 196).

A formulação de Braga foi, portanto, inovadora no sentido de ampliar a noção de financeirização para além do reconhecimento de uma supremacia de um setor sobre outros. Ao longo da década de 2000, após o estouro da bolha de ações nos Estados Unidos e em meio à percepção de que uma bolha de ativos imobiliários estava substituindo a bolha de ações para fomentar o crescimento do consumo na maior potência econômica do mundo, um número crescente de pesquisadores passou a considerar mais seriamente a ideia de financeirização, sobretudo no mundo anglo-saxão. Embora muitos deles tenham retido uma noção eminentemente keynesiana de uma supremacia do setor financeiro que estaria entravando a acumulação produtiva, muitos outros procuraram atentar para novas práticas sociais que têm, por fundamento, a onipresença de uma "lógica financeira geral", usando os termos de Braga.

Assim, por exemplo, Krippner (2005) demonstrou, utilizando zelosamente dados disponíveis para a economia americana, a centralidade dos rendimentos financeiros (juros, dividendos, etc) para as grandes firmas multinacionais (industriais) sediadas nos Estados Unidos. Igualmente, Robin Blackburn (2006) salienta o fato de que as grandes firmas multinacionais gerenciam complexos departamentos financeiros que respondem por parte substancial de suas receitas, ainda que a conclusão de Blackburn seja muito próxima a de alguns keynesianos que argumentam em favor de maior regulação estatista para erradicar a "disfuncionalidade" induzida pela financeirização. McNally (2009), por sua vez, argumenta que

o que o termo financeirização deveria capturar (...) é um conjunto de transformações por meio das quais as relaçóes entre capitais e entre capital e trabalho assalariado tornaram-se crescentemente financeirizadas - ou seja, crescentemente enraizadas em transações financeiras geradoras de juros (p. 56). ${ }^{1}$

Lapavitsas (2009), apontando a insuficiência de certos aspectos da teoria de Rudolph Hilferding sobre o capital financeiro para pensar a financeirização contemporânea, adota, em linhas gerais, perspectiva semelhante ao afirmar que

1 Tradução nossa. Grifos no original. 
a financeirização (...) não equivale à dominação dos bancos sobre o capital comercial e industrial. Os capitais industrial e comercial são capazes de tomar empréstimos em mercados financeiros abertos, ficando, portanto, profundamente implicados em transações financeiras. As instituições financeiras buscaram novas fontes de lucratividade na expropriação financeira e atuando como bancos de investimento. Enquanto isso, os trabalhadores foram crescentemente arrastados para a esfera das finanças privadas a fim de satisfazer necessidades básicas, incluindo moradia, consumo, educação, saúde e provisões para a terceira idade (p. 146). ${ }^{2}$

O trecho final do excerto levanta questões que constituem uma dimensão central do processo de financeirização e que vêm recebendo maior atenção de pesquisadores nos anos recentes. Com efeito, não é imprudente afirmar que a penetração das finanças nas diversas dimensões da vida cotidiana consiste na differentia specifica do período recente em relação a outros momentos na trajetória da reprodução capitalista, ao menos em uma gama de países que não estão no centro da economia global. ${ }^{3}$

A integração de parcelas crescentes da população em cadeias de crédito que sustentam a reprodução cotidiana da força de trabalho tornou-se possível, de modo mais evidente, a partir dos últimos trinta anos. É verdade que já existiam formas de crédito que atingiam parcelas mais pobres - e, aqui, é pertinente lembrar o caso do crédito imobiliário subsidiado pelo Estado, que foi uma das formas privilegiadas, em diversos países, de fomentar o acesso à casa própria. Mas nunca antes o sistema de crédito formal fora capaz de conceder crédito a uma gama tão extensa de atividades cotidianas, desde a compra de imóveis e de bens de consumo duráveis até gastos com saúde e educação.

O que viabilizou tudo isso foi, entre outras coisas, uma ampla reformulação da estrutura do sistema de crédito capitalista em sua relação com a acumulação de capital, e as repercussões dessas mudanças sobre os bancos constituíram um nó central na equação. As medidas de liberalização financeira dos anos 1980 e o crescimento vertiginoso no volume de recursos controlados por investidores institucionais, desejosos por aplicá-los em títulos no mercado de capitais, incentivou as grandes empresas a financiar o investimento de modo direto mediante a emissão de papéis como debêntures e ações, processo que foi designado de desintermediação financeira. Essa situação representou imenso revés aos bancos comerciais, que até então eram as principais instituições a financiar o investimento produtivo. Os bancos viram-se forçados, portanto, a buscar fontes alternativas de rendimento e, nessa conjuntura, o crédito pessoal começou a aparecer como uma solução viável para assegurar a lucratividade dos bancos comerciais (Dymski, 2009; Dos Santos, 2009; Lapavitsas, 2009)4.

\footnotetext{
Tradução nossa.

3 A ressalva é importante, uma vez que é pertinente argumentar que esse movimento de (incorporar as classes trabalhadoras ao sistema financeiro) iniciou-se nos Estados Unidos muito antes, provavelmente já nos anos 1930. No entanto, mesmo nesse país, o período recente foi exuberante no que se refere à capacidade das transações financeiras de mediarem a relação entre indivíduos e empresas nos níveis mais locais da vida social.

4 O que não quer dizer que não houve reestruturações complicadas e, mesmo, falências. Nos anos 1980, nos EUA, houve uma onda de falências de bancos, que não conseguiam mais atrair depositantes em razão da concorrência com outros mecanismos de poupança, como os mutual funds.
} 
Vale dizer, igualmente, que essa reformulação do conteúdo da atividade bancária teria sido impossível sem uma onda de inovações financeiras que passam pelo uso mais disseminado de tecnologia da informação. Por um lado, o uso de computadores permitiu simplificar e agilizar a análise de crédito através do emprego de softwares que avaliam o perfil dos requerentes, cruzando dados como renda, estabilidade no emprego, patrimônio, etc., gerando uma pontuação que representa um determinado grau de risco. Com esse procedimento, que começou a ser difundido mais amplamente na década de 1990 nos países desenvolvidos, os bancos estabeleceram taxas de juros que, supostamente, cobririam os riscos embutidos no perfil traçado para cada devedor (Langley, 2008; Dos Santos, 2009). A outra ponta desse processo de inovação financeira encontra-se no crescente uso de mecanismos de securitização de ativos. A securitização consiste no processo de converter determinado fluxo de renda em um ativo apto a ser negociado em mercados secundários, como é o caso dos famigerados mortgage-backed securities que protagonizaram a crise subprime. Para os bancos comerciais, a securitização de ativos tem sido uma forma atrativa de aumentar o volume de concessão de empréstimos e, ao mesmo tempo, contornar regulamentações que determinam a razão entre o montante de reservas e o volume de empréstimos (Leyshon \& Thrift, 2007). Se é verdade que a securitização ainda é um processo incipiente no Brasil e em outros países periféricos, seu uso vem crescendo em conformidade com esforços envidados pelos governos para aprimorar os mercados financeiros através de reformas diversas.

O que importa registrar aqui, todavia, é que esse surto na concessão de crédito pessoal representou um entrelaçamento profundo e inaudito das cadeias de crédito nos interstícios mais recônditos da vida social, com consequências relevantes. Cada vez mais, o crédito e as finanças medeiam a relação entre os indivíduos, impõem ritmos no uso do tempo e engendram um ethos que define as expectativas e modela as disposições subjetivas dos indivíduos. Paul Langley chama a atenção para esse gênero de mudanças subjetivas ao observar, a respeito dos devedores, que "[na esteira do] boom de crédito ao consumidor, (...) a prudência e a parcimônia foram substituídas por novas autodisciplinas morais e calculadoras relacionadas com o repagamento, a gestão e a manipulação de um volume crescente de obrigações financeiras pendentes" (Langley, 2006, p. 135).

Embora as considerações tecidas até aqui terem pouca relação direta com o que segue, seu sentido consiste em advertir para o caráter complexo e multifacetado das práticas financeirizadas que permeiam um espectro cada vez maior de transações econômicas e relações sociais no capitalismo contemporâneo. É esse caráter multifacetado e expansivo exibido pelo processo, que sugere a necessidade de se atentar para o enorme potencial de investigação colocado pela relação entre financeirização e a produção do espaço urbano. Se Leyshon \& Thrift (2007) estiverem corretos ao afirmar que um dos traços centrais da financeirização consiste na paulatina agregação de novos fluxos de rendimento que possam ser objeto de securitização

5 Tradução nossa. 
e, posteriormente, de especulação financeira em mercados secundários, então era evidentemente previsível que o mercado imobiliário seria, mais cedo ou mais tarde, absorvido na dinâmica financeira geral que vem definindo o capitalismo recente. A questão central para a pesquisa em Geografia urbana, porém, consiste em desvendar as repercussóes e desdobramentos desse processo para a produção do espaço urbano na contemporaneidade.

A problemática colocada pelos elos entre o financeiro e o imobiliário não é exatamente nova para a Geografia e outras ciências humanas. Ela despertou considerável interesse, nos anos 1980, em pesquisadores do mundo anglo-saxão, em parte em decorrência da projeção adquirida pela ideia defendida por Harvey em seu livro Limits to capital (Harvey, 1999), de que haveria uma tendência à transmutação do solo e seus melhoramentos em uma forma de capital fictício; mas o interesse também veio de um reconhecimento da presença de poderosos interesses financeiros na renovação das áreas de negócios (central business districts) das grandes metrópoles do mundo desenvolvido e, posteriormente, no colapso de bolhas imobiliárias em várias localidades 6 .

Mais recentemente, sobretudo - como foi salientado na introdução - em função da pletora de questões importantes suscitadas pelo colapso do mercado imobiliário americano, uma gama de pesquisas vem tentando decifrar a trama de relações econômicas e sociais que permite reler a produção do espaço através da noção de financeirização (Newman, 2009; Sassen, 2009, 2010; Aalbers, 2008; Gotham, 2006, 2009; Theurillat, Corpataux \& Crevoisier, 2010; Cattaneo, 2011). Não é preciso aqui retomar em detalhe cada contribuição, bastando sublinhar que os objetos de reflexão agora englobam temas diversos, e não se restringem apenas ao mundo anglófono. Nesse contexto, é interessante notar o crescimento do número de pesquisas que têm se voltado, ainda que nem sempre explicitamente, a essas questões no Brasil (Fix, 2007, 2011; Botelho, 2007; Miele, 2008; Volochko, 2008, 2011; Martins, 2010; Shimbo, 2010), visto que o problema dos nexos entre o sistema financeiro e a produção do espaço havia sido pouco investigado até recentemente, exceção feita aos estudos sobre as políticas públicas de financiamento habitacional.

A diversidade de ângulos sob os quais a relação entre financeirização e a produção do espaço urbano vem sendo analisada serve de testemunho à complexidade e à profundidade da problemática, bem como alerta para a necessidade de mais estudos que desvendem, em suas múltiplas facetas, os conteúdos dessa relação. Nas páginas que seguem, pretendemos colocar em perspectiva, ainda que sinteticamente, algumas das repercussões do processo de financeirização para a produção das

6 A interlocução dos autores com as reflexões de Harvey muitas vezes aparece de modo implícito, mas o emprego do termo "circuito secundário", por exemplo, para caracterizar o setor imobiliário e o investimento no ambiente construído de modo geral é um reconhecimento da influência do autor, que popularizou o termo inicialmente cunhado por Henri Lefebvre. De toda forma, é provável que o principal fator a despertar o interesse na questão foi a ampla reestruturação urbana que teve lugar, na década de 1980, nas principais metrópoles do mundo capitalista, e a presença de investidores financeiros nessas mudanças. Um panorama do debate acadêmico desse período pode ser acessado através de algumas publicações principais, como Harvey (1989; 1999); Feagin (1987); Gottdiener (1994); Haila (1988); Beauregard (1994). 
metrópoles no Brasil contemporâneo. Privilegiaremos, como eixo de análise, as grandes incorporadoras em sua atuação para além das metrópoles nacionais (São Paulo e Rio), o que se justifica pelo fato de que a expansão territorial dos negócios imobiliários urbanos sinaliza, possivelmente, uma ruptura com um padrão de urbanização anterior, um argumento que pretendemos desenvolver nas páginas a seguir. A atenção às grandes incorporadoras decorre, ademais, de um entendimento de que esses agentes funcionam como elos mediadores privilegiados entre as vicissitudes e volatilidades dos fluxos financeiros globalizados e o dia-a-dia da produção e reprodução do espaço urbano das grandes metrópoles. Esperamos, ao fim, não apenas corroborar com a ideia que intitula a presente seção do artigo de que a financeirização possui sentidos múltiplos, mas também apontar para mudanças de ordem socioespacial que sugerem estarmos diante de um rearranjo escalar do processo de urbanização no Brasil que precisa ser objeto de reflexão zelosa.

\section{A produção do espaço urbano sob o ritmo das finanças: tendências e desdobramentos}

Uma série de circunstâncias econômicas fez com que a securitização de ativos emergisse como uma das pedras angulares do capitalismo nos últimos trinta anos, permitindo um avanço de uma lógica financeira em quase todas as relações econômicas e sociais travadas entre empresas, governos e indivíduos. O fundamento desse processo repousa sobre a capacidade inédita, adquirida pelo sistema financeiro capitalista, de transmutar todo e qualquer fluxo de rendimento estável e duradouro em um título financeiro passível de ser negociado em mercados secundários e de ser, portanto, objeto de especulação (Leyshon \& Thrift, 2007).

A aparentemente inesgotável fonte de rendimentos contínuos oriundos da produção e do consumo do ambiente construído urbano não escapou a essa lógi$\mathrm{ca}$, de tal forma que os esforços por criar instrumentos financeiros que permitam ao investidor obter uma fatia dos rendimentos gerados no âmbito dos negócios imobiliários urbanos vêm caracterizando a dinâmica do capitalismo recente. No Brasil, essa tendência sempre definida pela presença do Estado, começa a se esboçar já na década de 1990, com a criação de instrumentos como os fundos de investimento imobiliários (FII) e os Certificados de Recebíveis Imobiliários (CRIs). Pode-se dizer que o Estado atuou, nesses últimos 20 anos no Brasil, em pelo menos dois níveis, e essa atuação constitui um fator essencial para explicar o recente boom imobiliário, o que justifica um breve excurso.

Em um nível mais geral, o Estado assentou as bases para a transformação do país no que Paulani (2008) designou por plataforma de valorização financeira internacional. A gama de ações que sustentou essa metamorfose, permitindo assim que o país passasse a ser visto com bons olhos por investidores financeiros internacionais, é vasta: desde um compromisso mais sério em honrar as dívidas do Estado mediante austeridade fiscal (sobretudo com corte de gastos sociais) e privatizações, passando pela diminuição da máquina pública, até as medidas de 
liberalização financeira e comercial e de estímulo ao investimento estrangeiro direto. Sem essas medidas, que receberam enorme impulso no governo Fernando Henrique Cardoso (1994-2002), a financeirização dos negócios imobiliários urbanos, que tem nos investidores institucionais estrangeiros um dos seus pilares, seria inconcebível.

Mas em um nível mais imediato, essa transformação reflete um esforço consciente e direcionado do Estado brasileiro no sentido de criar um aparato regulatório propício à circulação do capital no ambiente construído urbano e à criação de papéis lastreados por fluxos de rendimento imobiliário. Não é preciso recuperar em detalhe as medidas implementadas pelo Estado, desde a aprovação de fundos de investimento imobiliário em 1993, até a sanção da lei do Sistema de Financiamento Imobiliário (SFI) em 1997. Importa aqui chamar a atenção para seus sentidos: por um lado, esse rol de medidas visou proporcionar segurança jurídica para os credores (imobiliários) ao aprimorar as condições de execução da garantia hipotecária, sobretudo através da lei da alienação fiduciária, embutida na legislação do SFI; por outro, essas medidas regulamentaram a criação de títulos lastreados por hipotecas e de outros canais financeirizados de investimento imobiliário, como é o caso dos fundos de investimento imobiliário, bem como induziram uma série de outras intervenções regulatórias - como isenções fiscais - com o fito de aprimorar a liquidez nos mercados secundários para esses papéis (Botelho, 2007; Royer, 2008).

Essa arquitetura estatista foi fundamental para desatar um surto de crédito imobiliário a partir de meados da década de 2000, um momento em que, do ponto de vista macroeconômico, houve uma estabilização da economia brasileira em torno de variáveis positivas de crescimento e inflação. Para dar uma ideia do que se passou nesses últimos anos, basta destacar que o volume de unidades habitacionais financiadas no Brasil saltou de uma média de 250 mil por ano, entre 2000 e 2005, para mais de 1 milhão em 2010, e esse número tende a crescer. Também cresce, nesse contexto, a emissão de instrumentos financeiros cujos rendimentos originam-se na produção e consumo do ambiente construído urbano, como as cotas de fundos de investimento imobiliário. Foi esse cenário que configurou o pano de fundo para uma expansão vigorosa da atividade imobiliária por todo o país a partir de 2006, um processo fortemente marcado pela influência de grandes incorporadoras - a maior parte sediada em São Paulo - que alavancaram seus investimentos levantando capital na bolsa de valores de São Paulo (Bovespa). É esse contexto que nos interessa diretamente aqui, porque é plausível sugerir que seus desdobramentos apontam para uma situação relativamente nova no que se refere aos negócios com a propriedade no urbano e, por conseguinte, à produção do espaço urbano.

É pertinente tratar a abertura de capital das grandes incorporadoras/construtoras como um ponto de inflexão singular no que tange ao processo em tela. A abertura de capital e a emissão de papéis como debêntures na bolsa de valores não equivale, evidentemente, à securitização de ativos imobiliários. Todavia, 
é absolutamente necessário entender esses vínculos das incorporadoras com o mercado de capitais como um produto desse mesmo ambiente, que originou outros instrumentos com lastro imobiliário como cotas de fundos de investimento imobiliário e certificados de recebíveis imobiliários. Todos esses instrumentos sugerem o poder crescente das finanças de se apropriar de rendimentos oriundos da reestruturação das metrópoles ${ }^{7}$. Ilustraremos esse processo, portanto, colocando em foco a atividade de seis grandes incorporadoras que levantaram volumes significativos de capital entre 2006 e 2007, examinando, ainda que apenas sumariamente, as ramificações desse fenômeno para pensar a cidade e o urbano na atualidade.

Em primeiro lugar, é preciso frisar que a integração das incorporadoras imobiliárias à dinâmica da bolsa de valores no Brasil é um fenômeno novo e, especialmente para esse setor, produziu um ambiente de negócios inteiramente diferenciado. Primeiramente, porque esse setor se caracterizou, historicamente, por um predomínio da empresa familiar, que administrava um número de canteiros compatível com um quadro gerencial reduzido. A maior parte das empresas familiares, mesmo de grande porte, raramente investia em mercados para além da sua região de origem, o que muda substancialmente com a entrada de grandes players capitalizados pela bolsa de valores. Em segundo lugar, esse momento é diferenciado porque, para além de um crescimento do volume de investimentos e do raio de operação das empresas, induziu a mudanças qualitativas na forma de conduzir os negócios imobiliários, decorrentes, primordialmente, da presença do investidor financeiro.

O Quadro 1 dá uma dimensão do fenômeno que se esboça a partir de 2006 e que está plenamente sedimentado quatro anos depois: há um crescimento exponencial no volume de negócios conduzidos pelas empresas selecionadas - e, de modo geral, por todas aquelas que abriram capital na bolsa. Em termos de unidades lançadas, há saltos que superam dez vezes em um intervalo de cinco anos: a Cyrela, por exemplo, passa de um número anual de lançamentos de 2733 unidades em 2005, para 27589 unidades em 2010; de modo ainda mais impressionante, a PDG aumenta de 2089 para 42616, entre 2005 e 2010 e a MRV salta de 2987 para 50136, entre 2006 e 2010. Os mesmos dados registrados em termos de preço dos lançamentos - uma estimativa de preços que as empresas denominam Valor Geral de Vendas - mostram um quadro de rápida expansão: empresas que possuíam um giro anual bem inferior a $\mathrm{R} \$ 1$ bilhão em 2005 (exceção feita à Cyrela), passam a ter um volume de lançamentos, em muitos casos, superior a $\mathrm{R} \$$ 5 bilhões - a PDG atingindo a marca de R 9 bilhões.

7 Deve-se ressaltar, ainda, que há crescente simbiose entre os principais papéis com lastro imobiliário. A título de exemplo, um fundo imobiliário pode ser formado para construir e gerenciar um prédio de escritórios, que gerará rendimentos para os cotistas do fundo. Mas a construção do prédio é delegada a uma empresa de capital aberto que levanta recursos para construir emitindo debêntures e ações na bolsa de valores, e as receitas da construção serão depois distribuídas a acionistas e debenturistas como dividendos e juros. Se houver envolvimento de bancos no financiamento de parte da construção, o banco pode, em tese, securitizar seus recebíveis imobiliários para recompor sua carteira de ativos. Essa é apenas uma hipótese plausível entre uma miríade de possibilidades. 
QUADRO 1 | Número de unidades lançadas e lançamentos em VGV

\begin{tabular}{|c|c|c|c|c|c|c|}
\hline \multicolumn{7}{|c|}{ NÚMERO DE UNIDADES LANÇADAS } \\
\hline & 2005 & 2006 & 2007 & 2008 & 2009 & 2010 \\
\hline Cyrela & 2.733 & 5.822 & 16.924 & 18.270 & 26.417 & 27.589 \\
\hline Gafisa & 2.446 & 3.755 & 14.236 & 34.893 & 13.426 & 26.398 \\
\hline MRV & N/A & 2.987 & 12.334 & 25.968 & 28.948 & 50.136 \\
\hline PDG Realty & 2.089 & 3.994 & 12.860 & 18.200 & 35.598 & 42.616 \\
\hline Rossi & 1.999 & 4.409 & 9.648 & 10.542 & $\cdot 16.456$ & 23.239 \\
\hline Even & N/A & 1.485 & 4.345 & 4.233 & 3.459 & 6.515 \\
\hline \multicolumn{7}{|c|}{ LANÇAMENTOS EM VALOR GERAL DE VENDAS（VGV) (BRL X 1000) } \\
\hline & 2005 & 2006 & 2007 & 2008 & 2009 & 2010 \\
\hline Cyrela & 1.211 .302 & 3.619 .970 & 5.393 .057 & 4.827 .437 & 5.678 .927 & 7.609 .882 \\
\hline Gafisa & 682.196 & 1.233 .916 & 2.919 .355 & 5.322 .156 & 2.789 .224 & 6.041 .703 \\
\hline MRV & $\mathrm{N} / \mathrm{A}$ & 337.337 & 1.199 .948 & 2.532 .985 & 2.586 .080 & 4.604 .000 \\
\hline PDG Realty & 592.207 & 761.715 & 2.259 .550 & 3.776 .750 & 5.454 .300 & 9.151 .250 \\
\hline Rossi & 395 & 1.158 .000 & 2.470 .000 & 2.723 .000 & 2.758 .000 & 4.798 .000 \\
\hline Even & N/A & 744.436 & 1.757 .753 & 1.435 .128 & 926.735 & 1.528 .026 \\
\hline
\end{tabular}

FONTE RELATÓRIO TRIMESTRAIS DAS EMPRESAS

O que possibilitou essa expansão sem precedentes? Em primeiro lugar, a abundância de crédito habitacional para segmentos de renda que até então possuíam escasso acesso a esses empréstimos. Esse fenômeno, que se deve tanto à conjuntura econômica de crescimento moderado quanto às mudanças regulatórias de estímulo ao crédito imobiliário, mencionadas anteriormente, incentivou as empresas a voltarem seus olhos ao dito "segmento econômico". Algumas delas, é verdade, já tinham como foco, desde o início, o mercado de classe média baixa - esse é o caso, por exemplo, da MRV. Mas várias delas precisaram se reajustar para atender a esse mercado, com todas as suas especificidades em termos de limites de custos e padrões construtivos. Isso foi possível estabelecendo departamentos com independência relativa do segmento de origem da empresa, ou - mais comumente - adquirindo empresas que já possuíam conhecimento especializado (a chamada expertise) nos segmentos de média e baixa renda.

Mas a expansão também foi possível porque as empresas saíram dos seus mercados de origem para procurar novos mercados onde pudessem cumprir as metas estabelecidas, principalmente, pelos investidores que adquiriram seus papéis. Dito de outro modo, em que pese o mercado imobiliário de São Paulo (onde a maior parte das empresas está sediada) ter dimensões gigantescas, a necessidade premente de satisfazer os investidores obrigou as empresas a buscar terrenos e negócios em locais distantes de seu mercado de origem. À exceção da Even, que exibiu um crescimento mais lento em comparação com as outras cinco em questão, todas as 
incorporadoras com as quais estamos lidando investem em mais de dez estados da federação - do extremo sul ao norte do país. Essa tendência também se consolidou no curto período entre 2005 e 2010, o que pode ser ilustrado pelo perfil geográfico dos lançamentos de duas das empresas do grupo selecionado: a Rossi e a Cyrela (Quadro 2 e Quadro 3). ${ }^{8}$

Os dados são claros a respeito da conduta das duas empresas, que ilustram o que, em maior ou menor grau, ocorreu com todas as que abriram capital: uma desconcentração do investimento para fora da região metropolitana de São Paulo, que sofre perda de participação relativa. A Cyrela fez $48 \%$ dos seus lançamentos na região metropolitana de São Paulo em 2007, uma cifra que cai para 29\% dois anos depois. O mesmo dado sofre declínio de $32 \%$ para $16 \%$ entre 2007 e $2010^{9}$ no caso da Rossi, e as regiões ganhadoras estão distribuídas por todo o país.

QUADRO 2 | Cyrela - Lançamentos

\begin{tabular}{|l|c|c|}
\hline \multirow{2}{*}{\multicolumn{1}{|c|}{ LOCAL }} & \multicolumn{2}{c|}{ VALOR GERAL DE VENDAS (VGV) - R\$ X 1000 } \\
\cline { 2 - 3 } & $\mathbf{2 0 0 7}$ & $\mathbf{2 0 0 9}$ \\
\hline São Paulo - Região Metropolitana & $48,3 \%$ & $29,4 \%$ \\
\hline São Paulo - Interior & $11,4 \%$ & $17,9 \%$ \\
\hline Rio de Janeiro & $15,1 \%$ & $12,8 \%$ \\
\hline Minas Gerais & $7,0 \%$ & $3,1 \%$ \\
\hline Espírito Santo & $4,7 \%$ & $4,6 \%$ \\
\hline Maranhão & $6,0 \%$ & $6,5 \%$ \\
\hline Rio Grande do Sul & $6,0 \%$ & $5,8 \%$ \\
\hline Bahia & $11,7 \%$ & $4,0 \%$ \\
\hline Outros & $0,0 \%$ & $15,9 \%$ \\
\hline
\end{tabular}

Fonte Relatórios anUais Cyrela.

QUADRO 3 | Rossi - Lançamentos

\begin{tabular}{|l|c|c|}
\hline \multirow{2}{*}{\multicolumn{1}{|c|}{ LOCAL }} & VALOR GERAL DE VENDAS (VGV) - R\$ X 1000 \\
\cline { 2 - 3 } & $\mathbf{2 0 0 7}$ & $\mathbf{2 0 0 9}$ \\
\hline São Paulo - Região metropolitana & $32,2 \%$ & $16,0 \%$ \\
\hline São Paulo (interior) & $21,1 \%$ & $22,0 \%$ \\
\hline Rio de Janeiro & $14,5 \%$ & $6,0 \%$ \\
\hline Rio Grande do Sul & $12,5 \%$ & $16,0 \%$ \\
\hline Minas Gerais & $0,0 \%$ & $16,0 \%$ \\
\hline Ceará & $0,0 \%$ & $4,0 \%$ \\
\hline Amazonas & $0,0 \%$ & $7,0 \%$ \\
\hline Distrito Federal & $0,0 \%$ & $3,0 \%$ \\
\hline Bahia & $0,0 \%$ & $2,0 \%$ \\
\hline Outros & $19,7 \%$ & $8,0 \%$ \\
\hline
\end{tabular}

FONTE Relatórios AnUais Rossi.

8 Para evitar excesso de informação, optamos por apresentar os dados somente para essas duas empresas.

9 Dados para 2009 estavam indisponíveis. 
A exuberância dos dados de crescimento não deve, todavia, ofuscar a visão para os percalços enfrentados por algumas dessas empresas. Um dos problemas mais recorrentes esteve relacionado com as parcerias que as empresas estabeleceram com incorporadoras regionais para ingressar em mercados distantes. Um dos traços definidores do mercado imobiliário é seu caráter irremediavelmente local: em poucas palavras, para que uma empresa consiga ser bem-sucedida em um determinado mercado, é preciso um conhecimento profundo da dinâmica desse mercado (em termos de vetores espaciais de investimento, de preferências do consumidor, etc), bem como uma inserção capilar nas redes de relações - com fornecedores, subcontratados, proprietários de terrenos, assim como com administradores públicos e políticos - que permite a prospecção eficaz de novos negócios e, por conseguinte, uma rentabilidade favorável (Ball, 1983). Disso decorre que, quando uma empresa se estabelece fora da sua região de origem, ela precisa, na maior parte das vezes, estabelecer parcerias com empresas locais, ou mesmo adquirir estas empresas, com o fito de obter a expertise necessária para operar na região nova. Foi no estabelecimento de parcerias desse gênero que apareceram problemas para algumas das empresas que expandiram suas operações pelo Brasil. Em entrevista com um dos diretores de incorporação da Brookfield, uma empresa que optou por uma dispersão mais cautelosa dos seus investimentos, o entrevistado afirma o seguinte:

a pulverização [dos investimentos] é um negócio que a gente vê com um certo receio. (...) Atuar em todas as regiões do Brasil, a gente teme perder um pouco de controle porque, na verdade, quando você tem que ir para uma outra praça, você tem que ter um reconhecimento do lugar, muitas vezes você tem que fazer parcerias com empresas locais, para te dar a expertise regional da coisa, e com isso você começa a perder um pouquinho o controle, dispersar a sua filosofia de trabalho. Como as três empresas [que se uniram para formar a Brookfield] eram empresas muito bem estruturadas no que faziam, a Company tinha uma expertise muito grande em São Paulo, a Brascan no Rio e a MB em Brasília e Goiânia, a gente tinha um controle total, eram empresas de vinte, trinta anos em cada região, então era uma coisa bem consolidada. Hoje, (...) as principais empresas que abriram capital se dispersaram atrás de landbank no intuito de "não vou concentrar o meu risco em certas regiões, eu vou dispersar para ter meu risco dispersado também”. Só que termina sendo um tiro no pé, porque hoje elas já estão colhendo um resultado de que, os parceiros não eram tão bons quanto elas esperavam; (...) eram empresas pequenas, em algumas regiões, que estavam acostumadas a tocar empreendimentos pequenos, e se viram diante de megaempreendimentos e não tinham estrutura pra fazer aquilo [etc]. Então tem muita empresa hoje começando a fazer o caminho de volta, o caminho de despulverizar, se concentrar um pouquinho mais. ${ }^{10}$

O que está posto aqui é uma tensão bastante aguda entre, de um lado, uma necessidade de expansão impelida pelas exigências de rentabilidade colocadas pelos novos acionistas das incorporadoras de capital aberto e, do outro, os riscos adicionais

10 Entrevista realizada em São Paulo em 06/10/2011 juntamente com César Simoni dos Santos e Sávio Miele, como parte de um esforço coletivo (Grupo de Levantamento e Análise de Dados Sobre o Mercado Imobiliário). Foram realizadas, no total, dez entrevistas em São Paulo. 
que decorrem da necessidade de atuar em regiões distantes com parceiros pouco conhecidos. Esse problema afetou, por exemplo, fortemente a Cyrela e a Gafisa, conforme evidenciaram outras entrevistas e pesquisas em jornais especializados. Empresas como a Cyrela, entre outras, foram então forçadas a revisar suas políticas de dispersão, voltando a priorizar seus mercados de origem mediante o término ou reavaliação de algumas parcerias, sem abrir mão por inteiro de investimentos em outros locais.

Outro obstáculo enfrentado pelas empresas teve relação com os desdobramentos da crise imobiliária americana em 2008 que, ao reduzir a confiança dos investidores, causou dificuldades às empresas em continuarem financiando seus investimentos no mercado de capitais. Mesmo que as circunstâncias tenham se revelado passageiras, observou-se um ritmo mais lento no crescimento dos lançamentos e, em alguns casos, como o da Gafisa, uma contração brusca no ano de 2009 (ver Quadro 1). O problema voltou a afetar as empresas em 2011, que tiveram um desempenho pífio na bolsa de valores. O fulcro do problema, aqui, está relacionado, evidentemente, com um desempenho ruim das empresas, mas focar isoladamente nesse ponto mascara uma tensão que surgiu entre os acionistas e as empresas. Segundo entrevistas realizadas, os novos acionistas - predominantemente fundos de investimento estrangeiros - careciam de um conhecimento mais profundo das especificidades do setor imobiliário e, por isso, adotaram parâmetros para avaliar o desempenho das empresas que muitas vezes entravam em choque com o que se consideraria sensato no ramo referido. É o caso, por exemplo, da forte ênfase no volume do banco de terrenos que caracterizou a postura dos investidores em relação às empresas, nos primeiros anos após a abertura de capitais. Dobrando-se ao poder dos novos acionistas, muitas empresas se precipitaram a comprar terrenos em um ritmo acelerado. Quando, em 2008, ficou claro que haveria uma desaceleração do crescimento por conta do declínio na capacidade de financiamento externo, algumas empresas exibiam uma posição pouco líquida (pouco dinheiro em caixa, e muito imobilizado em terrenos), o que trouxe problemas sérios - a queda brusca no investimento da Gafisa deve-se a esse cenário. Esse é um exemplo claro do tipo de tensões e desencontros que afloram como decorrência do processo de financeirização, sobretudo tendo em vista a especifidade do investimento imobiliário.

É preciso atentar para um terceiro aspecto da trajetória recente dessas incorporadoras que pode permitir estabelecer conexões mais firmes com as transformações dos espaços urbanos no Brasil atual. Trata-se do fato de que essas empresas altamente capitalizadas vêm priorizando, inequivocamente, a oferta de empreendimentos de enorme magnitude, uma tendência que pode ser observada parcialmente no Quadro 4 a seguir - Ainda que algumas empresas não tenham exibido uma tendência tão evidente nessa tabela, pelo menos três delas (Cyrela, Rossi e MRV) tiveram um aumento substancial no número médio de unidades por empreendimento entre 2005 e $2010^{11}$. Essa tendência

11 É preciso salientar que essa tabela deixa lacunas que subestimam a tendência referida. Quando, por exemplo, as empresas parcelam um grande terreno para transformá-lo em um "bairro planejado", com estratégias de marketing e plantão de vendas unificado, elas computam cada um dos prédios/casas que compõem o loteamento como um empreendimento à parte. Portanto, não se trataria, aqui, de um único empreendimento com centenas de unidades (o que, de fato, é), mas sim vários com poucas unidades. 
é reforçada por dados concernentes à média de unidades por empreendimento em São Paulo, que sofreu um aumento de $30 \%$ entre 2006 e 2010, e em Porto Alegre, onde o aumento foi superior a $40 \%$ no mesmo período ${ }^{12}$.

QUADRO 4 | Média de unidades por empreendimento

\begin{tabular}{|l|c|c|c|c|c|c|}
\hline & $\mathbf{2 0 0 5}$ & $\mathbf{2 0 0 6}$ & $\mathbf{2 0 0 7}$ & $\mathbf{2 0 0 8}$ & $\mathbf{2 0 0 9}$ & $\mathbf{2 0 1 0}$ \\
\hline Cyrela & 143 & 138 & 219 & 207 & 290 & 255 \\
\hline Even & N/A & 135 & 121 & 169 & 138 & 197 \\
\hline PDG Realty & 232 & 142 & 176 & 214 & 252 & 199 \\
\hline Rossi & 111 & 91 & 185 & 206 & 242 & 223 \\
\hline MRV & N/A & 38 & 82 & 168 & 208 & 300 \\
\hline
\end{tabular}

FONTE RELATÓRIOS ANUAIS DAS EMPRESAS.

A lógica que se inscreve nesse movimento é a da maximização da apropriação de rendas: a oferta de grandes empreendimentos, somente tornada possível pela capacidade de levantar somas assombrosas no mercado de capitais, funciona como uma espécie de economia de escala por intermédio da qual as incorporadoras podem ampliar a diferença entre a renda do solo atual (aquela paga ou permutada com o proprietário do terreno) e a renda do solo potencial colocada pela localização do terreno na totalidade do tecido urbano - diferença essa que Neil Smith (1996; 2007) designou por rent gap. Evidentemente que as estratégias de investimento variam, e as formas assumidas por esses empreendimentos são inúmeras: grandes condomínios de renda baixa nas franjas do tecido metropolitano; "bairros planejados" para segmentos de renda elevada; empreendimentos multifuncionais de alto padrão mesclando escritórios, shopping centers e unidades residenciais; enormes loteamentos de unidades unifamiliares no âmbito do programa Minha Casa, Minha Vida, etc. Mas seu fundamento repousa sobre a capacidade extraordinária - e as formas inovadoras - dessas incorporadoras de "escavar" rendas por todo o tecido metropolitano, modificando-o profundamente como resultado desse processo. ${ }^{13}$

Deve-se ter em mente, portanto, os elos entre a financeirização do setor imobiliário - o crescente acesso a recursos mediante emissão de papéis no mercado de capitais - e a oferta de empreendimentos cada vez mais ambiciosos, quando se quer compreender alguns dos traços que definem a produção do espaço urbano na atualidade. Não se trata de afirmar que esses empreendimentos inexistiam antes que se estabelecessem mais fortemente os vínculos com as finanças mediante o mercado de capitais, mas sim de chamar a atenção para a intensificação de um determinado padrão de urbanização que tem marcado o período neoliberal, não apenas no Brasil. Um exemplo dessas novas circunstâncias está na capacidade dessas empresas de produzirem, mais do que imóveis, localidades, ou novas centralidades que recosturam o tecido metropolitano de formas inéditas, um fenômeno até então,

2 Dados publicados, respectivamente, pela Embraesp e pelo Sinduscon-RS.

13 Daí a necessidade de recuperar e desenvolver o debate sobre a renda do solo urbano, um conceito que recebeu escassa atenção nos últimos anos. 
relativamente restrito a megacidades como São Paulo e Rio de Janeiro, mas que tem se manifestado em várias metrópoles nos últimos cinco anos. $\mathrm{O}$ uso intensivo da publicidade e o apelo a modos de vida mais plenos constituem forças que só podem ser mobilizadas de forma plena porque o poder financeiro dos grandes investidores globais encontra-se por trás desses agentes imobiliários. Assim, pode-se afirmar que o poder financeiro concentrado que, cada vez mais, encontra canais para se apropriar de rendas do solo urbano, contribui para a produção de um espaço urbano cada vez mais fragmentado, fraturado por linhas de rendimento econômico e de classe social que agora dividem não apenas as áreas centrais das periféricas, mas também as próprias zonas periféricas, as quais passam a contar com condomínios fechados que mimetizam aqueles das classes mais abastadas. Essas novas separações e fronteiras que se instalam no urbano exacerbam tendências que, de uma forma ou de outra, sempre estiveram presentes no processo de urbanização no Brasil.

Um olhar crítico para esse processo não pode perder de vista o caráter expropriativo de muitas das mudanças que vem sendo enaltecidas - não apenas pelos agentes do setor imobiliário, mas também por setores do governo - como soluções para o problema habitacional brasileiro. A escalada de preços de imóveis, a crescente fragmentação do espaço urbano, a truculência das remoções de favelas e o endividamento ascendente de parcelas da população, indicam que o crédito imobiliário e o estímulo à aquisição da casa própria mediante o endividamento estão longe de constituírem soluções viáveis para o problema habitacional, como o caso dos Estados Unidos recentemente demonstrou de modo exemplar. Deparamo-nos, na verdade, com discursos ideológicos que dissimulam os verdadeiros conteúdos dos processos, com o propósito de justificar a presença de poderosos interesses privados nas transformações urbanas atuais. Por trás desse véu mistificador, o processo de urbanização continua sendo fundamentalmente crítico (Damiani, 2009), reiterando segregações e separações que impedem a realização de uma sociedade mais justa.

\section{Financeirização como reordenamento escalar? Exploraçôes teóricas à guisa de conclusão}

O esforço por converter o ambiente construído urbano em um título financeiro, dotado de um grau mais ou menos elevado de liquidez, constitui condição sine qua non para que os grandes investidores institucionais possam se apropriar dessa fonte gigantesca de rendimentos. No Brasil, houve um nítido empenho por parte do Estado, nos últimos vinte anos, em aprimorar as condições jurídicas e institucionais que fortalecem os negócios com a propriedade privada do solo e as relaçóes desses negócios com o sistema financeiro. Como resultado dessas intervenções e reformas, o capital-dinheiro pode agora circular mais livremente pelo ambiente construído urbano, se apropriando das rendas geradas pelo processo de urbanização, sem jamais se desfazer por completo de sua figura de capital-dinheiro, uma vez que a reversibilidade - a possibilidade de renunciar a uma posição mediante a venda do título - constitui um traço central dos mercados financeiros liberalizados 
(Chesnais, 2002, 2005; Dumenil \& Levy, 2006; Serfati, 2006). Em outras palavras, o capital-dinheiro contorna os obstáculos colocados pela natureza intrínseca do investimento no ambiente construído urbano - a saber, a baixa liquidez e o longo tempo de giro - sem com isso abrir mão dos rendimentos gerados pelo processo de urbanização.

O que também está em questão é um reordenamento escalar do processo de urbanização no Brasil sem precedentes. Como resultado das mudanças descritas ao longo desse trabalho, cada vez mais agentes financeiros globais - fundos de pensão, seguradoras, mutual funds e hedge funds - aprimoram sua capacidade de extrair rendimentos a partir da ininterrupta reconfiguração dos espaços urbanos no Brasil. Trata-se, portanto, de uma situação em que rendas do solo apropriadas na escala local - nas dezenas de cidades que hoje compõem o raio de operação das grandes incorporadoras - circulam cada vez mais livremente pelos meandros de uma arquitetura financeira global dominada pelos grandes fundos de aplicação sediados, em grande parte, nos países desenvolvidos. Isso não significa, de forma alguma, que a escala local esteja em vias de dissolução, ou que esse nível escalar esteja completamente subordinado ao que ocorre na escala global. Na verdade, como demonstramos no trabalho, algumas das empresas estudadas enfrentaram dificuldades econômicas justamente por desconhecer ou ignorar as especificidades e idiossincrasias dos lugares em cujos mercados de imóveis decidiram ingressar. Não se trata, portanto, de uma configuração estável em que o global prepondera sobre o local, mas sim de vínculos forjados entre escalas que são ininterruptamente contestados e redefinidos no âmbito do processo social - o que vale dizer, encontra respaldo em uma bibliografia que vem examinando a escala como social e politicamente produzida (Smith, 1992; Brenner, 2009a; 2009b). A financeirização, em sua relação com a produção do espaço urbano, pode ser lida como um rearranjo escalar que articula, de forma inédita, as escalas global e local no cerne do processo de urbanização, com todas as tensões e contradições que esse processo engendra.

É preciso frisar, finalmente, que essa reconfiguração escalar produziu, como assinalamos brevemente, uma metamorfose dos termos que definem a produção do espaço metropolitano no Brasil. A presença de nexos financeiros na produção do espaço urbano redundou em um recrudescimento do processo de fragmentação socioespacial, sobretudo em razão da ênfase dos grandes grupos do setor imobiliário na oferta de mega-projetos que apontam para graus mais ou menos elevados de ruptura com o tecido urbano como decorrência de sua natureza "introvertida" separação por muros e cercas, integração de funções diferenciadas (moradia, trabalho, etc), segurança e controle de acesso, etc. Esses megaprojetos, como vimos, são a expressão material de uma potencialização dos negócios com a propriedade do solo urbano. Portanto, longe de representar uma solução para o crônico problema habitacional que sempre foi uma das marcas da urbanização brasileira, a expansão do crédito e o "boom" imobiliário dos últimos cinco a dez anos no país manifestam, em primeiro lugar, uma capacidade inaudita dos investidores financeiros de se apropriarem de rendas inmobiliárias oriundas da reconfiguração do espaço urbano nos 
pontos mais longínquos do território brasileiro. É para esse sentido que aponta uma crescente bibliografia na Geografia e em outros campos dos estudos urbanos. Esse trabalho pretendeu oferecer uma contribuição para o discernimento da questão, destacando o papel das grandes construtoras/incorporadoras como elos mediadores entre os fluxos financeiros globais e a captura de rendas do solo na escala local. Como procuramos deixar claro ao longo do trabalho, esse é apenas um dos ângulos por meio dos quais se pode examinar a relação entre financeirização e a produção do espaço urbano. OEURE

\section{Referências bibliográficas}

Aalbers, M. (2008). The financialization of home and the mortgage market crisis. Competition and Change, 12(2), 148-166.

Ball, M. (1983). Housing policy and economic power: the political economy of owner occupation. New York \& London: Methuen.

Beauregard, R. (1994). Capital switching and the built environment: United States 1970-89. Environment and Planning A, 26(5), 715-732.

Blackburn, R. (2006). Finance and the fourth dimension. New Left Review, 39, 39-70. Disponível em http://newleftreview.org/II/39/robin-blackburn-finance-and-the-fourth-dimension

Braga, J. C. S. (1997). Financeirização global: o padrão sistêmico de riqueza no capitalismo contemporâneo. In: J. L. Fiori \& M. C. Tavares, Poder e dinheiro: uma política de globalização. Petrópolis/RJ: Editora Vozes.

Brenner, N. (2009a). Restructuring, rescaling, and the urban question. Critical Planning, 16, 61-79. Disponível em http://as.nyu.edu/docs/IO/222/Brenner.Critical_Planning.2009.pdf

Brenner, N. (2009b). A thousand leaves: notes on the geographies of uneven spatial development. In R. Keil, \& R. Mahon (Eds.), Leviathan undone? Towards a political economy of scale (pp. 27-49). Vancouver: University of British Columbia Press.

Botelho, A. (2007). O urbano em fragmentos: a produção do espaço e da moradia pelas práticas do setor imobiliário. São Paulo: Annablume/FAPESP.

Cattaneo, R. A. (2011). Los fondos de inversión inmobiliaria y la producción privada de vivienda en Santiago de Chile: ¿un nuevo paso hacia la financiarización de la ciudad? EURE, 37(112), 5-22. Disponível em http://dx.doi.org/10.4067/S0250-71612011000300001

Chesnais, F. (2002). A teoria do regime de acumulação financeirizado: conteúdo, alcance e interrogaçôes. Economia e Sociedade, 11(1-18), 1-44. Disponível em http://econpapers.repec.org/Re PEc:euc:ancoec:v:18:y:2002:p:1-44

Chesnais, F. (2005). O capital portador de juros: acumulação, internacionalização, efeitos econômicos e políticos. In: F.Chesnais (Org.), A finança mundializada. São Paulo: Boitempo.

Damiani, A. L. (2009). Urbanização crítica e produção do espaço. Cidades (Presidente Prudente), 6(10), 307-339. Disponível em http://revista.fct.unesp.br/index.php/revistacidades/article/view/537

Dos Santos, P (2009). On the content of banking in contemporary capitalism. Historical Materialism, 17(2), 180-213. doi: http://dx.doi.org/10.1163/156920609X436171

Dumenil, G. \& Levy, D. (2006). Capital resurgent. Cambridge, MA: Harvard University Press. 
Dymski, G (2009). Racial exclusion and the political economy of the subprime crisis. Historical Materialism, 17(2), 149-179.

Feagin, J. R. (1987). The secondary circuit of capital: office construction in Houston, Texas. International Journal of Urban and Regional Research, 11(2), 172-192. doi: 10.1111/j.14682427.1987.tb00045.x

Fix, M. (2007). São Paulo cidade global: fundamentos financeiros de uma miragem. São Paulo: Boitempo.

Fix, M. (2011). Financeirização e transformações recentes no circuito imobiliário no Brasil. Campinas: Instituto de Economia/Unicamp (Tese de Doutorado).

Gotham, K. F. (2006). The secondary circuit of capital reconsidered: globalization and the US real estate sector. American Journal of Sociology, 112(1), 231-275. Disponível em http://www. tulane.edu/ kgotham/GothamAJSArticle.pdf

Gotham, K. F. (2009). Creating liquidity out of spatial fixity: the secondary circuit of capital and the subprime mortgage crisis. International Journal of Urban and Regional Research, 33(2), 355-371. doi: 10.1111/j.1468-2427.2009.00874.x

Gottdiener, M. (1994). The social production of urban space. Austin: University of Texas Press.

Haila, A. (1988). Land as a financial asset: the theory of urban rent as a mirror of economic transformation. Antipode, 20(2), 79-101. doi: 10.1111/j.1467-8330.1988.tb00170.x

Harvey, D. (1989). The urban experience. Baltimore: Johns Hopkins University Press.

Harvey, D. (1999). The limits to capital. New York: Verso.

Itoh, M. \& Lapavitsas, C. (1999). Political economy of money and finance. New York: St. Martin's Press.

Krippner, G. (2005). The financialization of the American economy. Socioeconomic Review, 3(2), 173 208. doi: $10.1093 /$ SER/mwi008

Langley, P. (2006). Securitizing suburbia: the transformation of Anglo-American mortgage finance. Competition \& Change, 10(3), 283-299.

Langley, P. (2008). Financialization and the consumer credit boom. Competition \& Change, 12(2), 133-147.

Lapavitsas, C. (2009). Financialised capitalism: crisis and financial expropriation. Historical Materialism, 17, 114-148. doi: http://dx.doi.org/10.1163/156920609X436153

Leyshon, A. \& Thrift, N. (2007). The capitalization of almost everything: the future of finance and capitalism. Theory, Culture \& Society, 24(7-8), 97-115. doi: http://dx.doi. org/10.1177/0263276407084699

Martins, F. E. S (2010). A (re)produção social da escala metropolitana: um estudo sobre a abertura de capitais nas incorporadoras e sobre o endividamento imobiliário urbano em São Paulo. São Paulo: Faculdade de Filosofia, Letras e Ciências Humanas da Universidade de São Paulo (FFLCH/USP) (Tese de Doutorado).

McNally, D. (2009). From financial crisis to world slump: accumulation, financialisation, and the global slowdown. Historical Materialism, 17(2), 35-83. Disponível em http://www.havenscenter.wisc.edu/files/FromFinancialCrisistoWorldSlump.pdf

Miele, S. A. (2008) O movimento da economia financeira na dinâmica imobiliária de São Paulo. São Paulo: Faculdade de Filosofia, Letras e Ciências Humanas da Universidade de São Paulo (FFLCH/USP). 
Newman, K. (2009). Post-industrial widgets: capital flows and the production of the urban. International Journal of Urban and Regional Research, 33(2), 314-31. doi: 10.1111/j.14682427.2009.00863.x

Paulani, L. (2008). Brasil delivery: servidão financeira e estado de emergência econômico. São Paulo: Boitempo.

Royer, L. (2009). Financeirização da política habitacional: limites e perspectivas. São Paulo: Faculdade de Arquitetura e Urbanismo da Universidade de São Paulo (FAU/USP) (Tese de Doutorado).

Sassen, S. (2009). When housing becomes an electronic instrument: the global circulation of mortgages - a research note. International Journal of Urban and Regional Research, 33(2), 411426. http://dx.doi.org/10.1111/j.1468-2427.2009.00868.x

Sassen, S. (2010). A savage sorting of winners and losers: contemporary versions of primitive accumulation. Globalizations, 7(1-2), 23-50. http://dx.doi.org/10.1080/14747731003593091

Serfati, C. (2006). A economia política da finança global. Revista Brasileira de Economia Política, 18, 7-38.

Shimbo, L. Z. (2010). Habitação social, habitação de mercado: a confluência entre Estado, empresas construtoras e capital financeiro. São Carlos: Escola de Engenharia de São Carlos (USP) (Tese de Doutorado).

Smith, N. (1992). Contours of a spatialized politics: homeless vehicles and the production of geographical scale. Social Text, 33, 54-81. Disponível em http://www.jstor.org/stable/466434

Smith, N. (1996). The new urban frontier. New York: Routledge.

Smith, N. (2007). Gentrificação, a fronteira e a reestruturação do espaço urbano. GEOUSP (São Paulo), 21, 15-31. Disponível em http://www.geografia.fflch.usp.br/publicacoes/Geousp/ Geousp21/Artigo_Neil.pdf

Theurillat, T., Corpataux, J. \& Crevoisier, O. (2010). Property sector financialisation: the case of Swiss pension funds (1992-2005). European Planning Studies, 2(18), 189-212. doi: $10.1080 / 09654310903491507$

Volochko, D. (2008). A produção do espaço e as estratégias reprodutivas do capital: negócios imobiliários e financeiros em São Paulo. São Paulo: LABUR ediçôes.

Volochko, D. (2011). Novos espaços e cotidiano desigual nas periferias da metrópole. São Paulo: Faculdade de Filosofia, Letras e Ciências Humanas da Universidade de São Paulo (FFLCH/USP) (Tese de Doutorado). 